\title{
Journal of Humanistic Mathematics
}

\section{Wrong Way}

Joseph Chaney

Indiana University South Bend

Follow this and additional works at: https://scholarship.claremont.edu/jhm

Part of the Mathematics Commons, and the Poetry Commons

\section{Recommended Citation}

Joseph Chaney, "Wrong Way," Journal of Humanistic Mathematics, Volume 12 Issue 1 (January 2022), pages 502-502. . Available at: https://scholarship.claremont.edu/jhm/vol12/iss1/37

(C)2022 by the authors. This work is licensed under a Creative Commons License. $\mathrm{JHM}$ is an open access bi-annual journal sponsored by the Claremont Center for the Mathematical Sciences and published by the Claremont Colleges Library | ISSN 2159-8118 | http://scholarship.claremont.edu/jhm/

The editorial staff of JHM works hard to make sure the scholarship disseminated in JHM is accurate and upholds professional ethical guidelines. However the views and opinions expressed in each published manuscript belong exclusively to the individual contributor(s). The publisher and the editors do not endorse or accept responsibility for them. See https://scholarship.claremont.edu/jhm/policies.html for more information. 


\title{
Wrong Way
}

\author{
Joseph Chaney \\ jchaney@iusb.edu
}

Let the drunkard's walk be memoryless so that each step is a new beginning. Suppose a man like your dad doesn't know where he is. He can't know where he's going. He moves randomly, driven by discrete impulses, although perhaps believing he knows what he's doing. That's why he goes rather than halting - alert to guidance. What are the odds that he tumbles into the river? Knowing nothing is one kind of wrong knowledge. A mathematician might have solved the equation, might have seen where his steps were leading by his leaninghis bias for the turbulent, the wet.

Postscript: This poem uses the problem of the "drunkard's walk" to describe how "your dad" died from drowning, based on Brett Berry's explanation in her blog post "The Drunkard's Walk Explained: Stochastic Processes, Markov Chains \& Random Walks" (Math Hacks, June 12, 2017; available at https://medium.com/i-math/the-drunkards -walk-explained-48a0205d304). It's possible to hear the phrase "your dad" as referring to the poem's speaker's father, through a sort of psychological (or merely linguistic) displacement. Explicit consideration of the mathematics of the tragic accident pushes the event even further from the emotional origin of the speaker's concern. In other words, I want to create a tension between the calmness of mathematical calculation and the agitation of grief and/or anger. 